\title{
Childhood Septicemia in Nepal: Documenting the Bacterial Etiology and Its Susceptibility to Antibiotics
}

\author{
Shamshul Ansari, ${ }^{1}$ Hari Prasad Nepal, ${ }^{1}$ Rajendra Gautam, ${ }^{1}$ Sony Shrestha, ${ }^{1}$ Puja Neopane, \\ Brihaspati Rimal, ${ }^{2}$ Fuleshwar Mandal, ${ }^{2}$ Safiur Rahman Ansari, ${ }^{3}$ and Moti Lal Chapagain ${ }^{1}$ \\ ${ }^{1}$ Department of Microbiology, Chitwan Medical College, Bharatpur, Chitwan, Nepal \\ ${ }^{2}$ Department of Biochemistry, Chitwan Medical College, Bharatpur, Chitwan, Nepal \\ ${ }^{3}$ Asian College for Advance Studies, Satdobato, Kathmandu, Nepal \\ Correspondence should be addressed to Shamshul Ansari; shamshulansari483@yahoo.com
}

Received 31 October 2014; Revised 5 December 2014; Accepted 11 December 2014; Published 25 December 2014

Academic Editor: Maurizio Sanguinetti

Copyright (C) 2014 Shamshul Ansari et al. This is an open access article distributed under the Creative Commons Attribution License, which permits unrestricted use, distribution, and reproduction in any medium, provided the original work is properly cited.

\begin{abstract}
Introduction. Children are among the most vulnerable population groups to contract illnesses. The varying microbiological pattern of septicemia warrants the need for an ongoing review of the causative organisms and their antimicrobial susceptibility pattern. Therefore, the objective of this study was to document the bacterial etiology of childhood septicemia and its antibiotic susceptibility profile. Methods. Cross-sectional type of study in 1630 suspected patients was conducted at CMCTH from January 2012 to December 2013. Blood samples were collected aseptically for culture. The organisms grown were identified by standard microbiological methods recommended by American Society for Microbiology (ASM) and subjected to antibiotic susceptibility testing by modified Kirby-Bauer disk diffusion method. Methicillin resistance was confirmed using cefoxitin and oxacillin disks methods. Results. Septicemia was detected in 172 (10.6\%) cases. Among Gram-positive organisms, coagulase negative staphylococci (CoNS) were leading pathogen and Acinetobacter spp. were leading pathogen among Gram-negative isolates. Vancomycin, teicoplanin, and clindamycin were the most effective antibiotics against Gram-positive isolates while amikacin was effective against Gram-positive as well as Gram-negative isolates. Methicillin resistance was detected in $44.4 \%$ of Staphylococcus aureus. Conclusions. This study has highlighted the burden of bacterial etiology for septicemia among children in a tertiary care center of central Nepal.
\end{abstract}

\section{Introduction}

Presence of bacteria within the blood stream, continuous or transient, is known as bacteremia, while the dissemination of bacteria throughout the body with evidence of systemic responses towards microorganism with variable severity is called septicemia [1]. Septicemia is a common cause of pediatric morbidity and mortality [2]. The high mortality rate varies between 30 and 70 percent and depends on several factors including virulence of the pathogen and host factor $[3,4]$. Bacteriological culture method to isolate the offending pathogen remains the gold standard method for the diagnosis of bacteremia and septicemia $[2,5]$. Organisms isolated from the bloodstream of patients with sepsis vary from area to area [6]. In Nepal, the majority of the bacteremia and septicemia cases are caused by a number of pathogens including coagulase negative staphylococci (CoNS), Staphylococcus aureus, Streptococcus spp., Enterobacter spp., Escherichia coli, Klebsiella pneumoniae, Salmonella spp., Acinetobacter spp., Citrobacter spp., and Pseudomonas spp. [1, 7, 8].

The rational use of antibiotics for varying microbiological pattern of septicemia in children warrants the need for an ongoing review of the causative organisms and their antimicrobial susceptibility pattern $[9,10]$. Uncontrolled use of various potent and broad-spectrum antibiotics has led to emergence of resistant strains which has become a major problem in various intensive care units. Therefore, understanding of common pathogens and their drug sensitivity pattern in a specific region demands the correct use of antibiotics. Due to constantly evolving antimicrobial resistant 
patterns, there is need for constant antimicrobial sensitivity surveillance. This will help clinicians provide safe and effective empirical therapies, develop rational prescription programs and make policy decisions, and finally assess the effectiveness of all [2].

The results of bacteriological cultures and antibiotic susceptibility tests method are time consuming that can take about 2-4 days, necessitating initial empirical treatment of suspected septicemia. Therefore, knowledge of the epidemiological and antimicrobial susceptibility patterns of common pathogens in a given area helps to inform the choice of antibiotics. In accordance with this, the present study was carried out to document the bacterial etiology of septicemia and its antibiotic sensitivity profile.

\section{Materials and Methods}

A cross-sectional type of study was carried out in bacteriology laboratory of Chitwan Medical College Teaching Hospital (a 600 bed hospital) in Narayani zone of central Nepal from January 2012 to December 2013.

2.1. Study Population. A total of 1630 patients during two years of study period between the ages of 1 month and 15 years having clinical features suggestive of septicemia (fever, shortness in breath, weakness, drowsiness, irritability, etc.) were enrolled in this study.

2.2. Sample Collection. Two milliliter $(\mathrm{mL})$ of blood samples from early age children and $5 \mathrm{~mL}$ of blood samples from late age children were collected aseptically (clearing the skin with $70 \%$ alcohol followed by $2 \%$ tincture of iodine) by clinicians, trained nurses, or laboratory staff using sterile syringe and needle by venipuncture. Immediately the blood samples were carefully transferred into the blood culture bottle containing $18 \mathrm{~mL}$ (if $2 \mathrm{~mL}$ blood sample) or $45 \mathrm{~mL}$ (if $5 \mathrm{~mL}$ blood sample) of Brain Heart Infusion broth to maintain a ratio of $1: 10$ of blood to broth. The blood culture bottles were labeled with the patient's name, age/sex, identification number, date, and time of collection.

2.3. Bacteriological Processing. The Brain Heart Infusion broth inoculated with blood was transported to the laboratory and incubated at $37^{\circ} \mathrm{C}$ in aerobic condition. All the bottles were examined for turbidity, hemolysis, and pellicle formation and subcultures were made on to sheep blood agar, chocolate agar, and MacConkey agar after overnight aerobic incubation. Blood agar and MacConkey agar plates were incubated overnight at $37^{\circ} \mathrm{C}$ in aerobic atmosphere while chocolate agar plates were incubated overnight at $37^{\circ} \mathrm{C}$ in $5 \%$ carbon dioxide $\left(\mathrm{CO}_{2}\right)$. Culture bottles were observed for turbidity and blind subcultures were performed each day. Final subcultures were done on the 10th day before reporting negative. Growth obtained was examined for colony and Gramstaining characteristics. Conventional biochemical tests were performed and identification of the organism was done by using standard microbiological methods [11]. A purity plate was employed to ensure that the inoculum used for the biochemical tests was pure.

2.4. Antibiotic Susceptibility Testing. All the isolates grown were subjected to antibiotic susceptibility testing by modified Kirby-Bauer disk diffusion method in compliance with Clinical and Laboratory Standards Institute (CLSI) guidelines using Mueller-Hinton agar standard media. The inhibition zone standards for antimicrobial susceptibility were considered from tables for interpretative zone diameters of CLSI [12].

Antibiotic disks (HiMedia Laboratories, Pvt. Limited, India) used were as follows: oxacillin $(1 \mu \mathrm{g})$, cefoxitin $(30 \mu \mathrm{g})$, vancomycin $(30 \mu \mathrm{g})$, teicoplanin $(30 \mu \mathrm{g})$, erythromycin $(15 \mu \mathrm{g})$, clindamycin $(2 \mu \mathrm{g})$, penicillin $\mathrm{G}(10 \mathrm{U})$, cephalexin $(30 \mu \mathrm{g})$, cotrimoxazole $(25 \mu \mathrm{g})$, gentamicin $(10 \mu \mathrm{g})$, amikacin $(30 \mu \mathrm{g})$, ofloxacin $(5 \mu \mathrm{g})$, cefixime $(5 \mu \mathrm{g})$, cefotaxime $(30 \mu \mathrm{g})$, ceftazidime $(30 \mu \mathrm{g})$, piperacillin $(100 \mu \mathrm{g})$, piperacillintazobactam $(100 / 10 \mu \mathrm{g})$, carbenicillin $(100 \mu \mathrm{g})$, amoxycillin $(10 \mu \mathrm{g})$, and nalidixic acid $(30 \mu \mathrm{g})$.

Staphylococcus aureus ATCC 25923 and Escherichia coli 25922 were used as control organisms for antibiotic sensitivity testing.

2.5. Identification of Methicillin Resistance in Staphylococcus aureus. Identification of methicillin resistant Staphylococcus aureus (MRSA) strains was carried out by using oxacillin $(1 \mu \mathrm{g})$ and cefoxitin $(30 \mu \mathrm{g})$ disks. Plates were incubated at $35^{\circ} \mathrm{C}$. Plates containing oxacillin disk were read following a 24-hour incubation period. The diameter of the zone of inhibition (ZOI) of growth was recorded and interpreted as susceptible or resistant according to the criteria of CLSI. Staphylococcus aureus isolates were deemed methicillin resistant when the ZOI was $\leq 10 \mathrm{~mm}$ with the oxacillin disk or $\leq 21 \mathrm{~mm}$ with the cefoxitin disk [13].

2.6. Ethical Aspects. Verbal consent in local language for this study was taken from the guardians of participating children. This study was approved by the Institutional Review Committee of Chitwan Medical College, Bharatpur, Nepal.

2.7. Data Analysis. Statistical analysis was performed using SPSS-11.5 version. Association of septicemia with gender and type of causative agents were assessed by using the chi-square test and others. $P$ values $<0.05$ were considered statistically significant.

\section{Results}

3.1. Age and Sex-Wise Distribution of Cases. During two years of study period, 1630 children aged between 1 month and 15 years were enrolled, from whom positive growth of bacteria was obtained in 172 cases (10.6\%). Of total enrolled cases, 1016 $(62.3 \%)$ were males and $614(37.7 \%)$ were females, whereas, out of total positive cases, $94(54.6 \%)$ were males and 78 (45.4\%) were females which was found to be statistically significant $(P=0.028)$. Suspected cases and positive cases were more or less equal in each age group (Table 1). 
TABLE 1: Distribution of total and positive cases.

\begin{tabular}{lcccc}
\hline \multirow{2}{*}{ Age } & \multicolumn{2}{c}{ Total cases $(n=1630)$} & \multicolumn{2}{c}{ Positive cases $(n=172)$} \\
& Male & Female & Male & 29 \\
\hline $1-11$ months & 210 & 136 & 28 & 22 \\
$1-5$ years & 295 & 187 & 26 & 15 \\
6-10 years & 269 & 144 & 18 & 12 \\
$11-15$ years & 242 & 147 & 22 & $78(45.4 \%)$ \\
\hline Total & $1016(62.3 \%)$ & $614(37.7 \%)$ & $94(54.6 \%)$ & 728 \\
\hline
\end{tabular}

TABLE 2: Distribution of bacterial isolates.

\begin{tabular}{|c|c|c|c|c|c|c|}
\hline Isolates & 1-11 months & $1-5$ years & $6-10$ years & $11-15$ years & Total (\%) & $P$ value \\
\hline Gram-positive & 34 & 19 & 17 & 12 & $82(47.7)$ & \multirow{12}{*}{0.388} \\
\hline Coagulase negative staphylococcus (CoNS) & 30 & 16 & 14 & 8 & $68(39.5)$ & \\
\hline Staphylococcus aureus & 3 & 2 & 1 & 3 & $9(5.2)$ & \\
\hline Enterococcus spp. & 1 & 1 & 2 & 1 & $5(3.0)$ & \\
\hline Gram-negative & 23 & 29 & 16 & 22 & $90(52.3)$ & \\
\hline Acinetobacter spp. & 8 & 8 & 6 & 8 & $30(17.5)$ & \\
\hline Citrobacter spp. & 0 & 3 & 0 & 1 & $4(2.3)$ & \\
\hline Enterobacter spp. & 2 & 8 & 1 & 2 & $13(7.6)$ & \\
\hline Pseudomonas aeruginosa & 8 & 4 & 3 & 2 & $17(9.9)$ & \\
\hline Klebsiella pneumoniae & 1 & 2 & 3 & 2 & $8(4.6)$ & \\
\hline Escherichia coli & 3 & 2 & 2 & 2 & $9(5.2)$ & \\
\hline Salmonella spp. & 1 & 2 & 1 & 5 & $9(5.2)$ & \\
\hline Total (\%) & $57(33.1)$ & $48(27.9)$ & $33(19.2)$ & $34(19.8)$ & $172(100)$ & \\
\hline
\end{tabular}

3.2. Distribution of Bacterial Isolates. Gram-positive as well as Gram-negative organisms were isolated from the blood samples. Gram-positive organisms constituted $47.7 \%$ while Gram-negative organisms constituted $52.3 \%$ but the difference was not found to be statistically significant $(P=0.388)$. Of total positive cases, CoNS were the most common isolates (39.5\%) followed by Acinetobacter spp. (17.5\%). 44.1\% (30/68) of the CoNS positive cases belonged to the age group of 1-11 months (Table 2).

3.3. Antibiotic Resistance Pattern. Vancomycin and teicoplanin were found to be hundred percent effective against Gram-positive isolates. Amikacin was found to be very good alternative antibiotic for Gram-positive as well as Gramnegative isolates with very minor resistance to it. Most of the Gram-positive isolates were resistant to erythromycin, cotrimoxazole, and $\beta$-lactam antibiotics. Most of the tested antibiotics were not effective against Gram-negative isolates and nearly all isolates were resistant to ampicillin. Methicillin resistance was observed in $35.5 \%$ of CoNS and $44.4 \%$ of Staphylococcus aureus isolates whereas nalidixic acid resistance (NARS) was observed in $33.3 \%$ of Salmonella spp. (Table 3).

\section{Discussion}

Bacterial infections are major causes of morbidity and mortality in children. The detection, identification, and susceptibility testing of a causative species of bacteremia are essential for the proper management of the patient. In this study, among 1630 children aged between 1 month and 15 years enrolled, positive growth of bacteria was found in 172 cases (10.6\%). High culture positivity rates have been reported by investigators from other countries, $44.9 \%$ from Nigeria [2], $44.8 \%$ from Jordan [14], and 22.9\% from India [5]. Various factors affect the rate of isolation of organisms from the blood. These include the degree of bacteremia, prior antibiotic therapy, presence of fastidious organisms, the collection time and process, the ratio of amount of blood collected to volume of liquid broth, and the prolonged storage or delay prior to plating on solid media [15]. However, our isolation rate is higher than the rate of bacterial growth $(4.2 \%)$ reported from Kathmandu, Nepal [7], where most of the cases were referred from other centers and probably had received antibiotics prior to blood collection in the study center.

In current study, the bacterial sepsis was suspected more in male children $(62.3 \%)$ than in female children $(37.7 \%)$ and the higher rate of bacterial isolation in males $(54.6 \%)$ compared to females (45.4\%) seen in this study was found to be statistically significant $(P<0.05)$. Our result is in accordance with Karki et al. from Nepal [7] and Nimri et al. from Jordan [14], who have also reported higher bacterial growth in male patients than female patients. The higher positivity rate of septicemia in male children may be because of several factors. Firstly, male children are affected more often and more severely by infectious diseases and their immune systems respond less effectively to vaccine. Secondly, the testosterone can also suppress the immunity in male 
TABLE 3: Antibiotic resistance profile of isolates.

\begin{tabular}{|c|c|c|c|c|c|c|c|c|c|c|c|c|c|c|c|c|c|c|c|c|}
\hline \multirow{2}{*}{ Isolated organisms } & \multicolumn{20}{|c|}{ Rate of resistance to different antibiotics tested } \\
\hline & OX & FOX & VAN & TEI & $\mathrm{E}$ & $\mathrm{CD}$ & $\mathrm{P}$ & CFX & COT & G & AK & $\mathrm{OF}$ & CFM & CTX & CAZ & PI & PIT & CAR & AMX & NA \\
\hline $\begin{array}{l}\text { Coagulase negative } \\
\text { Staphylococcus spp. }\end{array}$ & 29.4 & 35.3 & 0 & 0 & 51.5 & 26.5 & 88.2 & 80.9 & 67.6 & 55.9 & 2.9 & 32.4 & $\mathrm{X}$ & $\mathrm{X}$ & $\mathrm{X}$ & $\mathrm{X}$ & $\mathrm{X}$ & $\mathrm{X}$ & $\mathrm{X}$ & $\mathrm{X}$ \\
\hline Staphylococcus aureus & 33.3 & 44.4 & 0 & 0 & 55.6 & 22.2 & 88.9 & 77.8 & 44.4 & 44.4 & 0 & 22.2 & $\mathrm{X}$ & $\mathrm{X}$ & $\mathrm{X}$ & $\mathrm{X}$ & $\mathrm{X}$ & $\mathrm{X}$ & $\mathrm{X}$ & $\mathrm{X}$ \\
\hline Enterococcus spp. & 0 & $\mathrm{X}$ & 0 & 0 & 60.0 & 0 & 100 & $\mathrm{X}$ & $\mathrm{X}$ & 60.0 & 20.0 & 20.0 & $\mathrm{X}$ & $\mathrm{X}$ & $\mathrm{X}$ & $\mathrm{X}$ & $\mathrm{X}$ & $\mathrm{X}$ & $\mathrm{X}$ & $\mathrm{X}$ \\
\hline Acinetobacter spp. & $\mathrm{X}$ & $\mathrm{X}$ & $\mathrm{X}$ & $\mathrm{X}$ & $\mathrm{Y}$ & $\mathrm{X}$ & $\mathrm{X}$ & $\mathrm{X}$ & 56.7 & 26.7 & 10.3 & 20.0 & 76.7 & 66.7 & 77.3 & 60.0 & 43.3 & $\mathrm{X}$ & 83.3 & $\mathrm{X}$ \\
\hline $\begin{array}{l}\text { Pseudomonas } \\
\text { aeruginosa }\end{array}$ & $\mathrm{X}$ & $\mathrm{X}$ & $\mathrm{X}$ & $\mathrm{X}$ & $\mathrm{X}$ & $\mathrm{X}$ & $\mathrm{X}$ & $\mathrm{X}$ & $\mathrm{X}$ & 52.9 & 11.7 & 35.3 & 58.8 & 70.6 & 58.8 & 76.5 & 52.9 & 41.2 & 100 & $\mathrm{X}$ \\
\hline Citrobacter spp. & $\mathrm{X}$ & $\mathrm{X}$ & $\mathrm{X}$ & $\mathrm{X}$ & $\mathrm{X}$ & $\mathrm{X}$ & $\mathrm{X}$ & $\mathrm{X}$ & 50.0 & 75.0 & 0 & 25.0 & 0 & 50.0 & 50.0 & 50.0 & 25.0 & $\mathrm{X}$ & 100 & $\mathrm{X}$ \\
\hline Enterobacter spp. & $\mathrm{X}$ & $\mathrm{X}$ & $\mathrm{X}$ & $\mathrm{X}$ & $\mathrm{X}$ & $\mathrm{X}$ & $\mathrm{X}$ & $\mathrm{X}$ & 69.2 & 61.5 & 23.0 & 61.5 & 69.2 & 15.4 & 23.0 & 61.5 & 38.5 & $\mathrm{X}$ & 77.0 & $\mathrm{X}$ \\
\hline Klebsiella pneumoniae & $\mathrm{X}$ & $\mathrm{X}$ & $\mathrm{X}$ & $\mathrm{X}$ & $\mathrm{X}$ & $\mathrm{X}$ & $\mathrm{X}$ & $\mathrm{X}$ & 62.5 & 50.0 & 0 & 37.5 & 50.0 & 37.5 & 37.5 & 62.5 & 37.5 & $\mathrm{X}$ & 100 & $\mathrm{X}$ \\
\hline Escherichia coli & $\mathrm{X}$ & $\mathrm{X}$ & $\mathrm{X}$ & $\mathrm{X}$ & $\mathrm{X}$ & $\mathrm{X}$ & $\mathrm{X}$ & $\mathrm{X}$ & 77.8 & 66.7 & 11.1 & 33.3 & 22.2 & 55.5 & 66.7 & 77.8 & 55.5 & $\mathrm{X}$ & 77.8 & $\mathrm{X}$ \\
\hline Salmonella spp. & $\mathrm{X}$ & $\mathrm{X}$ & $\mathrm{X}$ & $\mathrm{X}$ & $\mathrm{X}$ & $\mathrm{X}$ & $\mathrm{X}$ & $\mathrm{X}$ & 44.4 & 22.2 & 0 & 33.3 & 33.3 & 55.5 & 44.4 & 55.5 & 22.2 & $X$ & 88.9 & 33.3 \\
\hline
\end{tabular}

Note: OX: oxacillin, FOX: cefoxitin, VAN: vancomycin, TEI: teicoplanin, E: erythromycin, CD: clindamycin, P: penicillin G, CFX: cephalexin, COT: cotrimoxazole, G: gentamicin, AK: amikacin, OF: ofloxacin, CFM: cefixime, CTX: cefotaxime, CAZ: ceftazidime, PI: piperacillin, PIT: piperacillin-tazobactam, CAR: carbenicillin, AMX: amoxycillin, NA: nalidixic acid, X: not tested.

children [16]. Thirdly, females have more powerful immune system than males. The production of estrogen by females can have a beneficial effect on the innate inflammatory response against bacterial pathogens [17].

The causative organisms vary from place to place. In this study, Gram-positive as well as Gram-negative organism was isolated from the blood samples. Gram-positive organisms constituted $47.7 \%$ while Gram-negative organisms constituted $52.3 \%$ but the difference was not found to be statistically significant $(P>0.05)$. The various causative agents of childhood septicemia in this study were CoNS (39.5\%) followed by Acinetobacter spp. (17.5\%), Pseudomonas aeruginosa (9.9\%), Enterobacter spp. (7.6\%), Staphylococcus aureus (5.2\%), Escherichia coli (5.2\%), Salmonella spp. (5.2\%), Klebsiella pneumoniae (4.6\%), Enterococcus spp. (3.0\%), and Citrobacter spp. (2.3\%). CoNS as the leading cause of childhood septicemia followed by Enterococcus spp., Escherichia coli, Klebsiella pneumoniae, and Pseudomonas aeruginosa were also reported by Nimri et al. from Jordan [14].

Coagulase negative staphylococci (CoNS) were found to be the most common etiology of septicemia in the present study. Our result is in agreement with other studies that reported CoNS as the most common bacteria isolated from children with sepsis [3]. Coagulase negative staphylococci were reported to have emerged as a major cause of nosocomial infections [18]. They are part of normal flora and their presence in blood cultures might indicate catheter and medical device-related sepsis or a contaminant of blood cultures [19]. The interpretation of their presence is a major concern for clinicians and clinical microbiology laboratories. The decision for therapy relies mostly on the observation of sepsis symptoms and the number of positive blood cultures. However, the criteria of multiple blood cultures could not be applied in this study in early age pediatric patients who could not undergo multiple venipuncture. Acinetobacter spp. was isolated from $17.5 \%$ of cases and was the second most common isolated organism.
Though penicillin is a primary drug against Grampositive organisms, such isolates in our study exhibited $80 \%$ resistance to it. This result concurs with the report of Karki et al. from Nepal, who also noticed that Staphylococcus spp., the important Gram-positive organisms, were the least susceptible to penicillin [7]. All of the Gram-positive isolates were susceptible to vancomycin and teicoplanin whereas clindamycin was effective against more than $70 \%$ isolates.

Despite widespread use of aminoglycosides (gentamicin and amikacin), development of resistance to this class of antibiotics remained low compared to other antimicrobial agents. Amikacin was found to be a very good alternative for Gram-positive as well as Gram-negative isolates with very minor isolates being resistant to it while nearly half of the isolates were resistant to gentamicin. This observation was confirmed by the reports that the majority of Grampositive as well as Gram-negative blood stream isolates were susceptible to amikacin [20-22]. Resistance to gentamicin has recently increased and it may be due to overuse or misuse of this antibiotic in patients $[23,24]$.

Resistance to macrolide (erythromycin) is also increasing; more than $50 \%$ of isolates were resistant to erythromycin and most of the Gram-positive isolates were resistant to cotrimoxazole in this study. Similar result indicating high resistance to erythromycin and cotrimoxazole was also documented by Rathod et al. from India [25]. While fluoroquinolone is predominantly a Gram-negative drug, it does have activity against Gram-positive organisms also. As a consequence of low cost and easy availability, there has been indiscriminate use of ciprofloxacin in Nepal. We identified resistance rate ranging from $20 \%$ in Enterococcus spp. to $61.5 \%$ in Enterobacter spp.

Third generation cephalosporins were also less effective against Gram-negative isolates in this study. The resistance of $15.4 \%$ was exhibited by Enterobacter spp. and $77.3 \%$ by Acinetobacter spp. In a similar study conducted by Omoregie et al. in Nigeria, $100 \%$ of Gram-negative isolates were resistant 
to third generation cephalosporins [13]. Ceftriaxone and ceftazidime are being used without laboratory guidance, especially as coverage antibiotic during surgery and as blind antibiotic in emergencies, which perhaps has resulted in bacterial resistance to this drug. Amoxycillin was also not effective against Gram-negative isolates, $77 \%$ to $100 \%$ of Gramnegative isolates were resistant to amoxycillin. Omoregie et al. from Nigeria have also observed that nearly all Gramnegative isolates were found to be resistant to amoxicillin [13].

Nowadays, the methicillin resistance in CoNS and Staphylococcus aureus (MRSA) is posing a great challenge to the treatment narrowing the regimen options for these resistant bugs. Prior antibiotic use is the most common risk factor for colonization and infection with MRSA. In this study, $35.5 \%$ of CoNS and $44.4 \%$ of Staphylococcus aureus isolates were found to be resistant to methicillin. This result corroborates with $30.7 \%$ MRSA observed in children suffering from bacteremia by Saravanan et al. in India [26]. Two different methods were employed for the detection of MRSA. The cefoxitin disk method detected $44.4 \%$ of MRSA cases while the oxacillin disk method detected $33.3 \%$ of MRSA. According to CLSI the cefoxitin disk test is comparable to the oxacillin disk test for the prediction of mecA-mediated resistance to oxacillin [27]. The cefoxitin disk test is easier to read and thus is the preferred method. Besides, cefoxitin is an inducer of the mecA gene.

The emergence of quinolone resistance in the most common Salmonella serotype worldwide is a serious public health concern. Resistance to nalidixic acid has been associated with reduced efficacy of fluoroquinolones such as ciprofloxacin and ofloxacin $[28,29]$. In current study, 33.3\% of Salmonella spp. were nalidixic acid resistant (NARS).

There was no attempt to isolate anaerobic bacteria in this study although they might have been the cause of bacteremia and septicemia in some of the cases where no aerobic bacteria were detected in blood cultures. Anaerobic bacteria were reported to constitute $18 \%$ of the total number of isolates from blood [30].

\section{Conclusions}

This study has highlighted the burden of bacterial etiology for septicemia among children in a tertiary care center of central Nepal. However, since the spectrum of pathogens, incidence of diseases, and antimicrobial susceptibility change over time and places, the data should be monitored continuously to allow an appropriate clinical response and healthcare planning. This study highlights the variable nature of antibiotic susceptibility patterns. Therefore, it is advisable to continuously evaluate the resistance pattern of isolates so as to make a rational use of antibiotics.

The present study identified the burden of MRSA infection among septicemic children. Regular monitoring of antibiotic susceptibility pattern of MRSA and selection of a definite antimicrobial agent may be helpful for reducing the incidence of MRSA infections in septicemia in children. It is also important for clinicians to be aware of the existence of the bacterial strains showing decreased fluoroquinolone susceptibility.

\section{Conflict of Interests}

The authors declare that they have no conflict of interests.

\section{Acknowledgments}

The authors are deeply indebted to the children and their parents for participating in this study. They also thank all the laboratory staff of the Bacteriology Department of Chitwan Medical College Teaching Hospital (CMCTH) for their kind support in the collection of data and performing the necessary laboratory tests during the study.

\section{References}

[1] R. Chaudhary, S. Karmacharya, S. Shrestha et al., "Incidence of Bacteremia and Septicemia in patients attending in tertiary care center of Nepal," Journal of Institute of Medicine, vol. 34, no. 3, pp. 32-38, 2012.

[2] M. M. Meremikwu, C. E. Nwachukwu, A. E. Asuquo, J. U. Okebe, and S. J. Utsalo, "Bacterial isolates from blood cultures of children with suspected septicaemia in Calabar, Nigeria," BMC Infectious Diseases, vol. 5, article 110, 2005.

[3] R. P. Wenzel, M. R. Pinsk, R. J. Ulevitch, and L. Young, "Current understanding of sepsis," Clinical Infectious Diseases, vol. 22, no. 3, pp. 407-412, 1996.

[4] A. P. Wheeler and G. R. Bernard, "Treating patients with severe sepsis," The New England Journal of Medicine, vol. 340, no. 3, pp. 207-214, 1999.

[5] M. Sharma, N. Goel, U. Chaudhary, R. Aggarwal, and D. R. Arora, "Bacteraemia in children," Indian Journal of Pediatrics, vol. 69, no. 12, pp. 1029-1032, 2002.

[6] J. Mugalu, M. K. Nakakeeto, S. Kiguli, and D. H. KadduMulindwa, "Aetiology, risk factors and immediate outcome of bacteriologically confirmed neonatal septicaemia in Mulago hospital, Uganda," African Health Sciences, vol. 6, no. 2, pp. 120 126, 2006.

[7] S. Karki, G. K. Rai, and R. Manandhar, "Bacteriological analysis and antibiotic sensitivity pattern of blood culture isolates in Kanti children hospital," Journal of Nepal Paediatric Society, vol. 30, no. 2, pp. 94-97, 2010.

[8] R. Pradhan, U. Shrestha, S. C. Gautam et al., "Bloodstream infection among children presenting to a general hospital outpatient clinic in urban Nepal," PLOS ONE, vol. 7, no. 10, Article ID e47531, 2012.

[9] N. Palikhe, "Prescribing pattern of antibiotics in Paediatric Hospital of Kathmandu Valley," Kathmandu University Medical Journal, vol. 2, no. 5, pp. 6-12, 2004.

[10] M. Sharma, A. Yadav, S. Yadav, N. Goel, and U. Chaudhary, "Microbial profile of septicemia in children," Indian Journal for the Practising Doctor, vol. 5, pp. 9-10, 2008.

[11] I. Hd, Clinical Microbiology Procedures Handbook, ASM Press, Washington, DC, USA, 2nd edition, 2004.

[12] Clinical and Laboratory Standard Institute (CLSI), "Performance standards for antimicrobial susceptibility testing," Wayne, Pa, USA, CLSI, M100-S16, 2006. 
[13] R. Omoregie, C. A. Egbe, H. O. Ogefere, I. Igbarumah, and R. E. Omijie, "Effects of gender and seasonal variation on the prevalence of bacterial septicemia among young children in Benin City, Nigeria," Libyan Journal of Medicine, vol. 4, no. 3, pp. 107-109, 2009.

[14] L. F. Nimri, M. Rawashdeh, and M. M. Meqdam, "Bacteremia in children: etiologic agents, focal sites, and risk factors," Journal of Tropical Pediatrics, vol. 47, no. 6, pp. 356-360, 2001.

[15] C. K. Shaw, P. Shaw, and A. Thapalial, "Neonatal sepsis bacterial isolates and antibiotic susceptibility patterns at a NICU in a tertiary care hospital in western Nepal: a retrospective analysis," Kathmandu University Medical Journal, vol. 5, no. 18, pp. 153$160,2007$.

[16] M. White, "Why do women have such stronger immune system than men?" 2014, http://www.psmag.com/navigation/healthand-behavior/girls-immune-systems-rule-boys-drool-73250/.

[17] Women have a more powerful immune system than men, 2009, http://phys.org/news161315351.html.

[18] N. B. Frebourg, S. Lefebvre, S. Baert, and J.-F. Lemeland, "PCR-based assay for discrimination between invasive and contaminating Staphylococcus epidermidis strains," Journal of Clinical Microbiology, vol. 38, no. 2, pp. 877-880, 2000.

[19] W. E. Kloos and T. L. Bannerman, "Update on clinical significance of coagulase-negative staphylococci," Clinical Microbiology Reviews, vol. 7, no. 1, pp. 117-140, 1994.

[20] H. E. Akalin, M. Torun, and R. Alacam, "Aminoglycoside resistance patterns in Turkey," Scandinavian Journal of Infectious Diseases, vol. 20, no. 2, pp. 199-203, 1988.

[21] A. Japoni, S. Farshad, A. Alborzi et al., "Epidemiology and antibacterial susceptibility patterns of bloodstream infections, 2001-2004: an experience with Bactec 9240 in Southern Iran," Pakistan Journal of Biological Sciences, vol. 11, no. 3, pp. 422-427, 2008.

[22] M. Barati, M. T. Taher, R. Abasi, M. M. Zadeh, M. Barati, and A. R. Shamshiri, "Bacteriological profile and antimicrobial resistance of blood culture isolates," Iranian Journal of Clinical Infectious Diseases, vol. 4, no. 2, pp. 87-95, 2009.

[23] A. Mohammad, "Bacteremia among Jordanian children at princess Rahmah hospital: pathogens and antimicrobial susceptibility patterns," Iranian Journal of Microbiology, vol. 2, no. 1, pp. 22-26, 2010.

[24] S. Harbarth, P. Rohner, E. Safran, J. Garbino, R. Auckenthaler, and D. Pittet, "Resistance to amikacin and gentamicin among Gram-negative bloodstream isolates hospital between 1989 and 1994," Clinical Microbiology and Infection, vol. 4, no. 4, pp. 199204, 1998.

[25] S. D. Rathod, P. V. Bhatia, P. H. Patel, J. D. Pethani, L. R. Patel, and B. Chauhan, "Bacteriological analysis and resistance pattern among various culture isolates from neonatal septicemia at tertiary care hospital of Ahmedabad," National Journal of Medical Research, vol. 2, no. 4, pp. 466-469, 2012.

[26] M. Saravanan, A. Nanda, and T. Tesfaye, "Antibiotic susceptibility pattern of methicillin resistant Staphylococcus aureus from septicemia suspected children in tertiary hospital in Hosur, South India," American Journal of Microbiological Research, vol. 1, no. 2, pp. 21-24, 2013.

[27] Clinical and Laboratory Standards Institute (CLSI), "Performance standards for antimicrobial susceptibility testing," in Proceedings of the 17th Informational Supplement, M100-S17, Clinical and Laboratory Standards (CLSI), Wayne, Pa, USA, 2007.
[28] J. Wain, N. T. T. Hoa, N. T. Chinh et al., "Quinolone-resistant Salmonella typhi in Viet Nam: molecular basis of resistance and clinical response to treatment," Clinical Infectious Diseases, vol. 25, no. 6, pp. 1404-1410, 1997.

[29] K. Mølbak, D. L. Baggesen, F. M. Aarestrup et al., "An outbreak of multidrug-resistant, quinolone-resistant Salmonella enterica serotype typhimurium DT104," The New England Journal of Medicine, vol. 341, no. 19, pp. 1420-1425, 1999.

[30] D. E. Anuradha, K. Saraswathi, and A. Gogate, "Anaerobic bacteraemia: a review of 17 cases," Journal of Postgraduate Medicine, vol. 44, no. 3, pp. 63-66, 1998. 

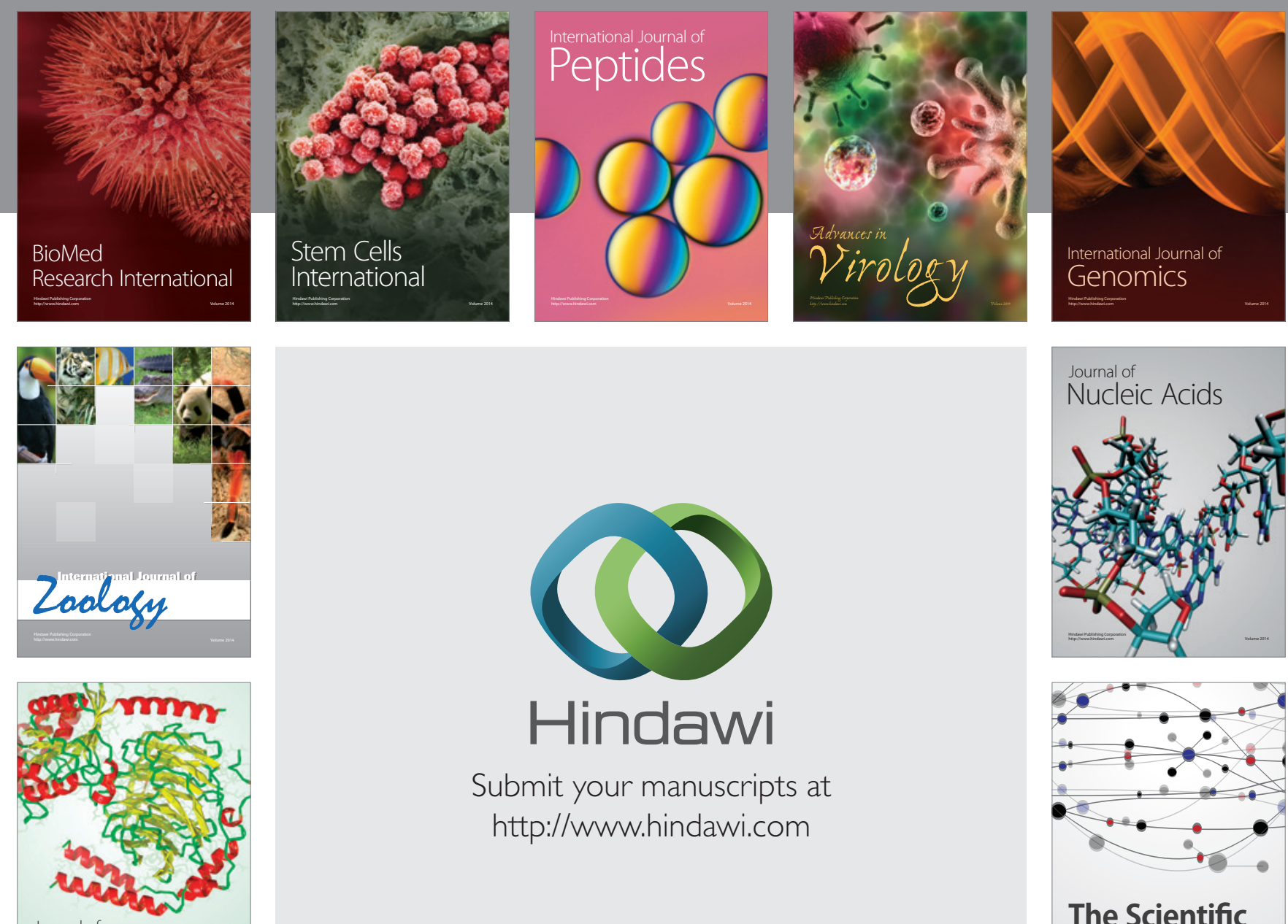

Submit your manuscripts at

http://www.hindawi.com

Journal of
Signal Transduction
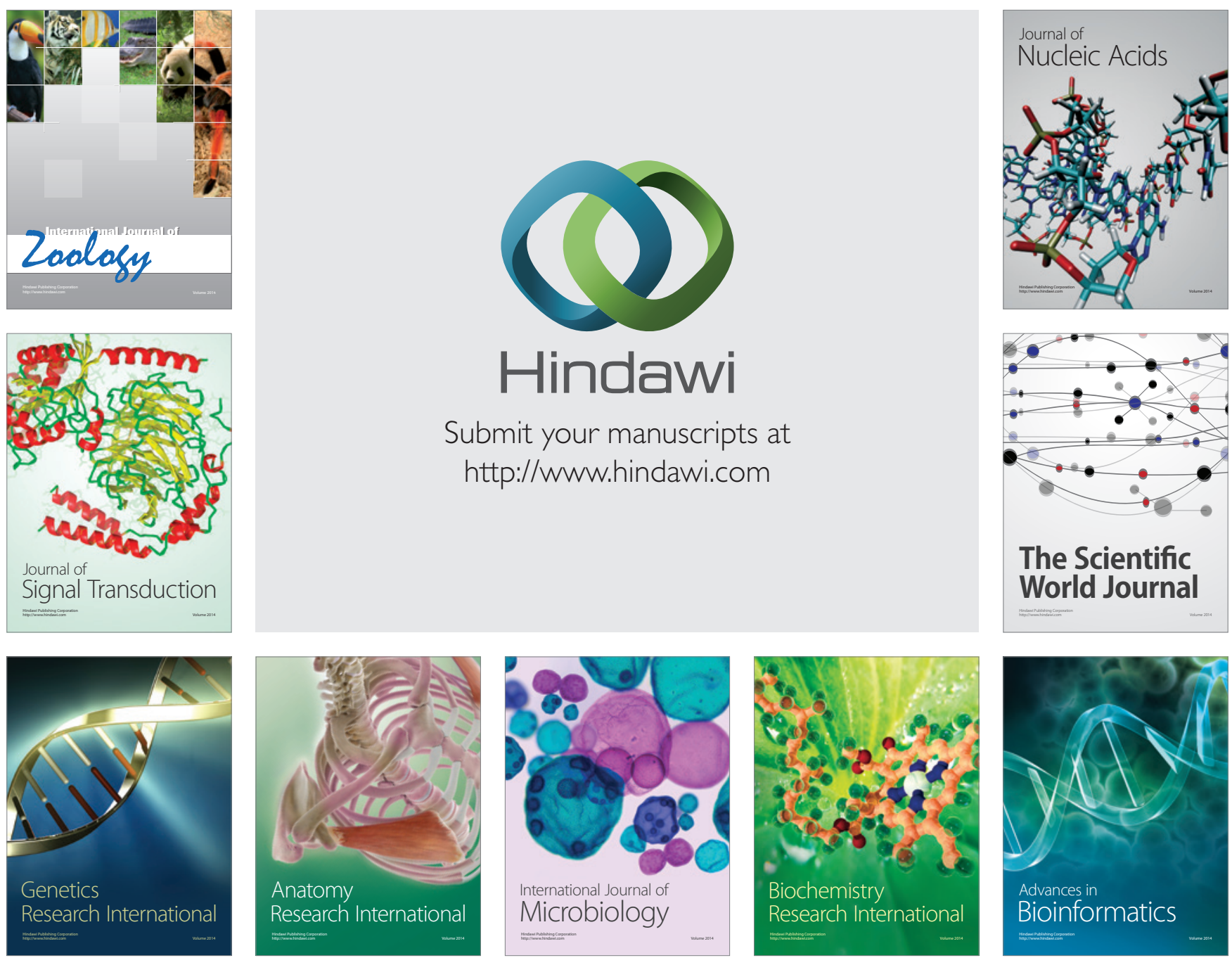

The Scientific World Journal
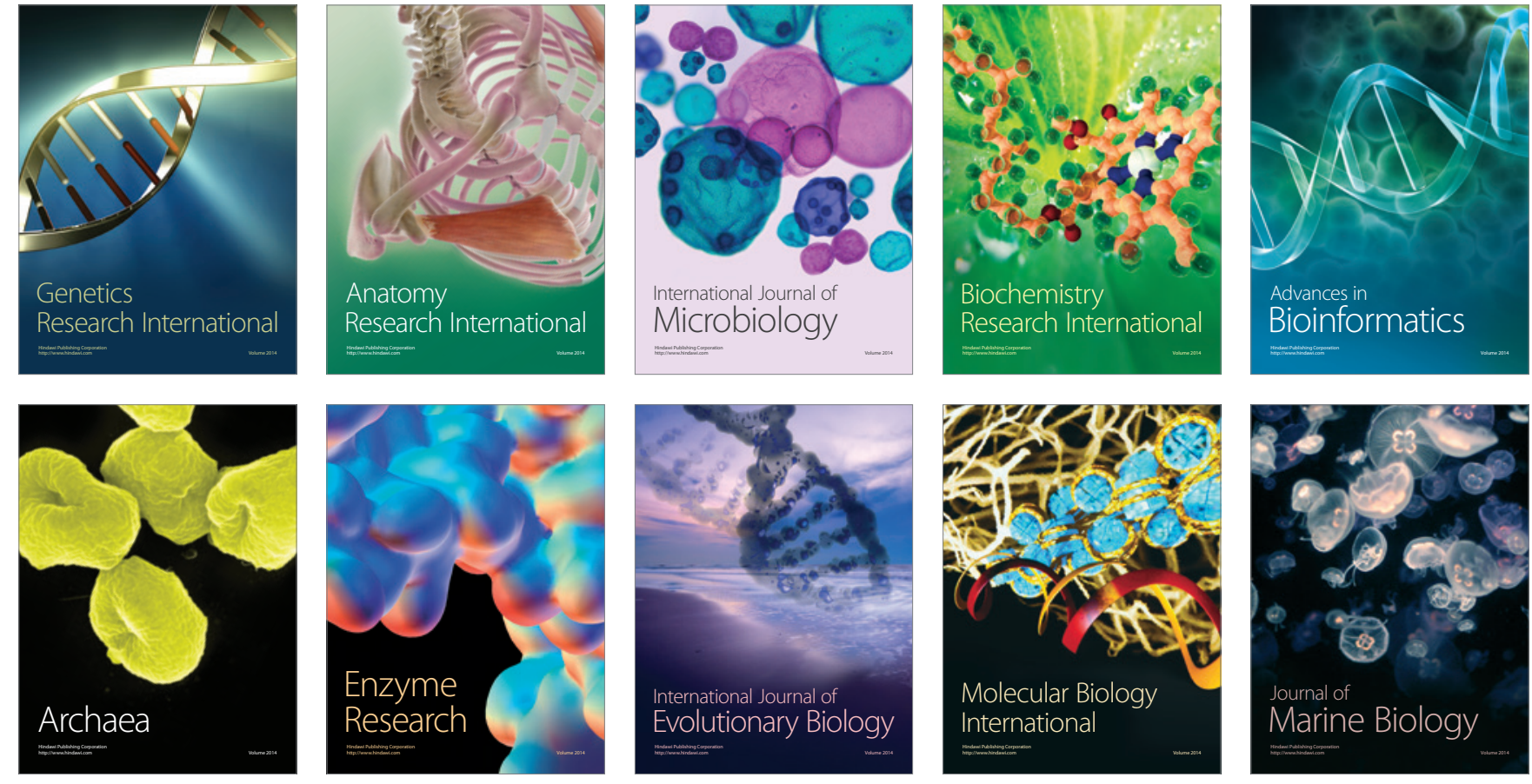